\title{
EL COMPLEJO AGAVE VICTORIAE-REGINAE (AGAVACEAE)
}

\author{
M. Socorro González-Elizondo, Martha GonzÁlez-Elizondo, \\ Irma L. López-EnRíQuez, LoRENZo ResÉnDIZ-RoJAS, \\ Jorge A. Tena-Flores y Flor Isela Retana-Rentería \\ Instituto Politécnico Nacional, Centro Interdisciplinario de Investigación \\ para el Desarrollo Integral Regional, Unidad Durango \\ Sigma 119, Fraccionamiento 20 de Noviembre II \\ 34220 Durango, Durango, México \\ herbario_ciidir@yahoo.com.mx
}

\begin{abstract}
RESUMEN
El nombre de Agave victoriae-reginae se ha aplicado a un grupo de plantas endémicas al norte de México fácilmente distinguibles de otras especies de Agave por tener hojas con márgenes córneos sin dientes, bandas blancas sobre ambas caras y flores con tubos cortos en forma de embudo. Su revisión taxonómica revela que lo que se conoce como A. victoriae-reginae es un complejo que incluye tres especies, una de ellas con dos subespecies: 1a) A. victoriae-reginae subsp. victoriae-reginae (del occidente de Nuevo León y extremo oriental de Coahuila; 1b) A. victoriae-reginae subsp. swobodae (sur de Coahuila y noreste de Durango); 2) Agave nickelsiae (microendémica al sureste de Coahuila); y 3) Agave pintilla (la de distribución más occidental del grupo, sureste de Durango). En este trabajo se describe Agave pintilla como entidad nueva, se reinstala A. nickelsiae como nombre correcto de una de las especies y se presentan descripciones enmendadas de $A$. victoriae-reginae subsp. victoriae-reginae, $A$. victoriae-reginae subsp. swobodae y A. nickelsiae, así como claves para distinguir entre taxa. No se encontraron híbridos naturales entre los miembros del complejo $A$. victoriae-reginae pero se registran tres con otras especies: Agave nickelsiae x A. asperrima, A. nickelsiae x A. lechuguilla, y A. pintilla x A. salmiana subsp. crassispina.
\end{abstract}

Palabras clave: Agavaceae, Agave victoriae-reginae, endemismo, hibridación, maguey noa, taxonomía. 


\section{ABSTRACT}

The name Agave victoriae-reginae has been applied to a group of plants endemic to northern Mexico which are easily distinguished from other species of Agave by having leaves with corneous, entire margins, white lines on both faces and flowers with short, funnelform tubes. A taxonomic revision reveals that A. victoriae-reginae represents a complex of three species, one of them with two subspecies: 1a) Agave victoriae-reginae subsp. victoriae-reginae (western Nuevo León and eastern extreme of Coahuila; 1b) A. victoriae-reginae subsp. swobodae (southern Coahuila and northeastern Durango); 2) Agave nickelsiae (microendemic to southeastern Coahuila); and 3) Agave pintilla (the most westernly distributed species in the group, restricted to southeastern Durango). Agave pintilla is here described as new, the name of A. nickelsiae is reinstated, and A. victoriaereginae is circumscribed. A key to the taxa as well as ammended descriptions for $A$. victoriae-reginae subsp. victoriae-reginae, $A$. victoriae-reginae subsp. swobodae and $A$. nickelsiae are provided. No natural hybrids were found among the taxa of the Agave victoriae-reginae complex but three natural hybrids with other species are recorded: Agave nickelsiae x A. asperrima, A. nickelsiae x A. lechuguilla, and A. pintilla x A. salmiana subsp. crassispina.

Key words: Agavaceae, Agave victoriae-reginae, endemic, hybridization, noah, taxonomy.

\section{INTRODUCCIÓN}

El nombre Agave victoriae-reginae T. Moore (Agavaceae) se ha aplicado tradicionalmente a un grupo de plantas endémicas del norte de México, muy apreciadas por coleccionistas y viveristas debido a su valor ornamental. Está enlistado en la NOM-059-SEMARNAT-2010 como especie en peligro de extinción (Anónimo, 2010) y en el Apéndice II de CITES (Convención sobre el Comercio Internacional de Especies Amenazadas de Fauna y Flora Silvestres). Agave victoriae-reginae forma parte del subgénero Littaea por tener inflorescencia sin ramificaciones aparentes y hojas con margen entero. Fue incluida por Gentry (1982) en el grupo Marginatae por tener los márgenes de las hojas córneos y las flores con tubos cortos en forma de embudo.

Bajo el nombre $A$. victoriae-reginae se engloba a plantas fácilmente distinguibles de otras especies de Agave por presentar una combinación de característi- 
cas única: hojas con bandas blancas sobre ambas caras, con márgenes córneos sin dientes y flores con tubos cortos en forma de embudo. El nombre ha sido usado de manera general para ese grupo por muchos autores (p. ej. Gentry, 1982; González Elizondo et al., 1991, 2009; Ullrich, 1991b; Espejo y López-Ferrari, 1992; GarcíaMendoza, 1995, 2002, 2003; Chávez Ávila y Martínez-Palacios, 1996; Eguiarte et al., 1999; Martínez-Palacios et al., 1999; Díaz Ramírez et al., 2004; Villarreal-Quintanilla, 2001; Villarreal-Quintanilla y Encina-Domínguez, 2005, entre otros). Sin embargo, entre las plantas tradicionalmente consideradas como A. victoriae-reginae existen algunas que difieren considerablemente en la forma de la roseta, el número, forma y color de las hojas, el tamaño y la forma de las flores y el hábitat que ocupan, reconociéndose en este trabajo cuatro taxa dentro del grupo.

\section{MATERIALES Y MÉTODOS}

Se llevó a cabo una revisión taxonómica de las plantas que han sido tratadas bajo el nombre de $A$. victoriae-reginae, cubriendo las poblaciones previamente registradas y otras detectadas por primera vez durante este trabajo. Se recopiló y sistematizó la información disponible sobre su taxonomía, biología, genética y estado poblacional. Se examinaron las colecciones en los herbarios ANSM, CFNL, CIIDIR, ENCB, MEXU y UNL.

Se realizaron 16 salidas de muestreo o de prospección en los estados de Nuevo León, Coahuila y Durango; para las plantas registradas en campo se tomaron los siguientes datos: diámetro, altura y cantidad de hojas de la roseta; largo, ancho y color de las hojas y, cuando presentaban inflorescencia, su altura, diámetro, forma número de ramificaciones y color de las flores. En los casos en que fue necesario colectar muestras se herborizó una hoja y, cuando las había, se herborizaron muestras de flores y de brácteas, así como flores en una solución de alcohol $70 \%$ y glicerina (autorización de Licencia de colecta científica sobre especies o poblaciones en riesgo o sobre hábitat crítico: Oficio Núm. SGPA/DGVS/03368/09). Los ejemplares testigo se depositaron en el herbario CIIDIR.

La revisión taxonómica de los componentes del complejo Agave victoriaereginae se llevó a cabo mediante métodos convencionales de comparación de caracteres morfológicos, ecológicos y de distribución geográfica. Para poder adjudicar los nombres correctos a los taxa que se reconocieron, se revisaron aspectos taxonómicos y nomenclaturales. La cita de los autores se basa en Villaseñor et al. (2008). 


\section{RESULTADOS Y DISCUSIÓN}

La revisión taxonómica del grupo revela que lo que se ha tratado previamente bajo el nombre de A. victoriae-reginae representa un complejo de cuatro taxa que difieren considerablemente en la forma de la roseta, el número, forma y color de las hojas, el tamaño y la forma de las flores, el hábitat que ocupan y la distribución geográfica. Los caracteres diagnósticos se presentan en el Cuadro 1 y en la clave para distinguir los taxa. Se reconocen tres especies, una de ellas con dos subespecies:

\section{Agave victoriae-reginae T. Moore}

1a. Agave victoriae-reginae T. Moore subsp. victoriae-reginae

1b. Agave victoriae-reginae subsp. swobodae J. J. Halda

2. Agave nickelsiae Goss. ex Rol.-Goss.

3. Agave pintilla S. González, M. González \& L. Reséndiz

Todos los componentes del complejo se desarrollan únicamente sobre substratos de origen sedimentario, principalmente roca caliza y, en menor proporción, sobre coluviones o conglomerado, rara vez arenisca.

En el presente trabajo el reconocimiento de taxa se fundamenta en diferencias morfológicas de carácter discreto, aunadas a las características ambientales de los hábitats y a la distribución geográfica de las cuatro entidades. A continuación se comentan las diferencias parciales entre la clasificación que se propone aquí y los resultados de dos estudios moleculares y fitoquímicos.

Una comparación de los patrones de variación en 10 loci de alozimas polimórficas (Chávez Ávila y Martínez-Palacios, 1996; Martínez-Palacios et al., 1999) indica que los componentes del complejo Agave victoriae-reginae presentan altos niveles de variación genética intrapoblacional y un particularmente alto nivel de diferenciación entre las poblaciones, al grado de que cada una de ellas parece representar una unidad evolutiva independiente, con niveles de diferenciación comparables a aquellos observados entre diferentes subespecies o aún entre especies en muchos géneros de plantas (Martínez-Palacios et al., 1999). Lo anterior podría ser un punto a favor para sustentar la separación de taxa que se propone en el presente trabajo, pero no es así, pues los tres conjuntos sometidos al análisis de alozimas no corresponden con los taxa aquí reconocidos, particularmente en el caso de $A$. nickelsiae, el cual difiere marcadamente de $A$. victoriae-reginae a nivel morfológico, pero en el estudio de alozimas aparece (como "población 3") con afinidad con las plantas de A. victoriae- 
Cuadro 1. Comparación entre algunos caracteres morfológicos de Agave victoriae-reginae subsp. victoriae-reginae (A v-r v-r), A. victoriae-reginae subsp. swobodae (A v-r swob), $A$. nickelsiae y A. pintilla.

\begin{tabular}{|c|c|c|c|c|}
\hline & A v-r v-r & A v-r swob & A. nickelsiae & A. pintilla \\
\hline Roseta (forma) & $\begin{array}{l}\text { compacta, globosa } \\
\text { a deprimido- } \\
\text { globosa }\end{array}$ & $\begin{array}{l}\text { compacta, } \\
\text { oblongo-globosa }\end{array}$ & $\begin{array}{l}\text { subcompacta o } \\
\text { abierta }\end{array}$ & abierta \\
\hline Hojas (número) & $(150-) 280-500$ & $70-180$ & $170-280$ & $60-180$ \\
\hline $\begin{array}{l}\text { Hojas } \\
\text { (superficie) }\end{array}$ & $\begin{array}{l}\text { verde a verde } \\
\text { limón, no } \\
\text { puberulentas }\end{array}$ & $\begin{array}{l}\text { verdes, no } \\
\text { puberulentas }\end{array}$ & $\begin{array}{l}\text { verde gris a } \\
\text { verde opaco, } \\
\text { puberulentas }\end{array}$ & $\begin{array}{l}\text { verde pálido } \\
\text { azuloso, no } \\
\text { puberulentas }\end{array}$ \\
\hline $\begin{array}{l}\text { Hojas (cm } \\
\text { largo) }\end{array}$ & $(7-) 10-22$ & $6-12$ & $13-23$ & $13-22$ \\
\hline $\begin{array}{l}\text { Hojas (cm } \\
\text { ancho) }\end{array}$ & $3.6-4.8$ & $1.5-4.5$ & $5.5-8.5$ & $5.8-8$ \\
\hline Hojas (forma) & $\begin{array}{l}\text { lanceoladas a } \\
\text { estrechamente } \\
\text { oblongas }\end{array}$ & $\begin{array}{l}\text { estrechamente } \\
\text { oblongas a } \\
\text { angostamente } \\
\text { triangulares }\end{array}$ & oblongas & $\begin{array}{l}\text { angostamente } \\
\text { triangulares }\end{array}$ \\
\hline $\begin{array}{l}\text { Perianto (cm } \\
\text { largo) }\end{array}$ & 2.6-3.6 & $2.6-3.2$ & $4-4.4$ & $4-4.4$ \\
\hline $\begin{array}{l}\text { Filamentos } \\
\text { (mm largo) }\end{array}$ & $20-48$ & $20-30$ & $60-66$ & $58-66$ \\
\hline
\end{tabular}

reginae subsp. victoriae-reginae (poblaciones 1 y 2). Lo anterior parece indicar que en este complejo la evolución de las alozimas ha seguido un camino independiente al de la diferenciación morfológica.

Una comparación de perfiles ISTR (Ávila Sevilla, 2010) revela niveles de polimorfismo hasta de $100 \%$ en A. victoriae-reginae subsp. victoriae-reginae, lo que sugiere una alta variabilidad genética, pero no indica una correlación directa entre los perfiles ISTR y los taxa reconocidos en este trabajo a excepción de Agave pintiIla, la cual se separa claramente del resto del grupo (esa especie no fue incluida en el estudio de alozimas por no haberse descubierto aún).

Un análisis de los perfiles fenólicos foliares (Ávila Sevilla, 2010) indica que en el complejo A. victoriae-reginae predominan los ácidos fenólicos y en segundo lugar los flavonoides, similarmente a lo encontrado por Almaráz-Abarca et al. (2009) para detectar variabilidad intra e interespecífica en Agave durangensis y especies 
relacionadas. Al igual que en los perfiles ISTR, Agave pintilla está claramente diferenciada del resto del grupo.

La parafilia a nivel molecular y fitoquímico puede ocurrir por diversas razones, entre las cuales están: a) asincronía en la evolución a nivel molecular, morfológico (Hörandl, 2010) y bioquímico, con los cambios morfológicos usualmente requiriendo más tiempo para manifestarse; b) falta de congruencia entre las filogenias obtenidas para diferentes genes (Gaut et al., 2000); c) los cambios importantes para la especiación pueden residir en unos pocos loci no detectados por los marcadores RAPD (Navarro-Quezada et al., 2003). Por lo anterior, es necesario usar de manera complementaria la información molecular de cloroplasto, mitocondria y núcleo, adicionalmente a la información morfológica.

En A. victoriae-reginae subsp. victoriae-reginae se registra también variación intrapoblacional a nivel morfológico, particularmente en la forma y el color del ápice de las hojas y en el tipo y tamaño de la espina. Good-Ávila et al. (2006) reportan que Agave es un género joven, de entre 7.8 y 10.1 millones de años de antigüedad, encontrando que hubo en él etapas de alto grado de especiación: hace 6 a 8 millones de años y posteriormente entre 2.5 a 3 millones de años. La diversidad de fenotipos y de hábitats encontrada para el complejo de A. victoriae-reginae y la presencia del grupo en áreas que han sufrido fuertes modificaciones climáticas durante el Pleistoceno, sugiere un activo proceso de especiación en el grupo. El reconocimiento de los taxa que forman parte del complejo A. victoriae-reginae es un avance sustantivo para la comprensión del grupo y para facilitar acciones para su conservación, pero aún se requieren estudios que combinen datos morfológicos con otros basados en fitoquímica, citogenética, biología molecular y filogeografía, así como trabajos ecológicos para mejorar el conocimiento sobre las variables que determinan la distribución de los taxa del complejo y otros de biología de poblaciones que permitan interpretar mejor los patrones morfológicos y demográficos en el grupo.

Taxonomía

Clave para identificar a los taxa del complejo A. victoriae-reginae:

1 Rosetas compactas, de color verde a verde limón, hojas densamente imbricadas, las de la parte media ascendentes o curvadas hacia el eje central, truncadas a redondeadas en el ápice, con espina mucroniforme, acicular o lanceolada; flores 2.6-3.6 cm de largo (3.5-7 cm incluyendo estambres) .................................... 2 
2 Rosetas globosas a deprimido-globosas; hojas lanceoladas o estrechamente oblongas, (7-)10-22 cm de largo; en hojas secas el margen córneo es continuo hasta el ápice A. victoriae-reginae subsp. victoriae-reginae

2 Rosetas oblongo-globosas; hojas estrechamente oblongas a angostamente triangulares, 6-12 cm de largo; en hojas secas el margen córneo frecuentemente está separado en la parte distal

A. victoriae-reginae subsp. swobodae

1 Rosetas abiertas o subcompactas, de color verde grisáceo o verde pálido a azuloso, hojas medias ascendentes o divergentes, no curvadas hacia el eje de la planta, redondeadas a agudas en el ápice, con espina lanceolada o piramidal; flores 3.8-4.4 cm de largo (7-8.8 cm incluyendo estambres) 3

3 Hojas 170-280, las de la parte media de la planta ascendentes (roseta subcompacta en plantas maduras), de color verde gris a verde opaco, puberulentas, oblongas, ventralmente convexas, algo angostadas cerca de la base, ápice redondeado, espina decurrente sobre los ángulos de la hoja, la franja blanca apical 1(-2) mm de ancho; flores en grupos de tres, tépalos y filamentos con tinción púrpura ............................................................................ A. nickelsiae

3 Hojas 60-180, las de la parte media de la planta divergentes (roseta abierta en plantas maduras), de color verde a verde pálido azuloso, no puberulentas, angostamente triangulares, ventralmente planas o cóncavas, más anchas cerca de la base, ápice agudo gradualmente continuándose con la espina lanceolada, ésta no o apenas decurrente, la franja blanca apical 5-10 mm de ancho; flores en grupos de dos, tépalos blanquecinos a blanco verdosos, filamentos blanquecinos o con leve tinción púrpura A. pintilla

1. Agave victoriae-reginae T. Moore, Gardener's chronicle, new series 4: 484, 485. 1875. Lectotipo (designado por Ullrich, 1991). Fig. 101 de Moore, 1875: 485.

El nombre de la especie se dedicó a la Reina Victoria (1819-1901) de Inglaterra. La historia de la descripción de esta magnífica especie y los vanos esfuerzos de Carrière $(1875 \mathrm{a}, 1875 \mathrm{~b})$ por dar prioridad al nombre de $A$. consideranti se comentan por Ullrich (1991b).

Dado que en la descripción original de A. victoriae-reginae no se seleccionó tipo, la ilustración original fue designada (Ullrich, 1991a) como lectotipo (Art. 9.2 IUCN), substituyendo al neotipo designado por Gentry (1982) (Art. 9.11 IUCN). 
Roseta solitaria o a veces cespitosa, rara vez surculosa, acaule o con tallo corto no visible, compacta, globosa, deprimido-globosa u oblongo-globosa; hojas (70-)200 a alrededor de 500, densamente imbricadas, de color verde a verde limón con bandas blancas angostas sobre las dos caras y los márgenes, rígidas o rara vez flexibles, lanceoladas o estrechamente oblongas, aquilladas o rara vez redondeadas sobre el dorso, a veces de sección casi triangular, conduplicadas o ventralmente cóncavas excepto hacia la base donde presentan un engrosamiento, 6-22 cm de largo, 1.5-4.8 cm de ancho; márgenes córneos, blancos o grises, 1-3 mm de ancho, enteros, el margen continuo hacia la base y hacia el ápice o en la subsp. swobodae con frecuencia desprendido en la mitad distal; ápice de la hoja truncado o redondeado, rara vez agudo, destacando el color verde o usualmente el blanco de la banda; espina terminal recta o retorcida, desde muy corta y mucroniforme hasta subulada y acicular, rara vez lanceolada, con la base amplia o estrecha, 0.4-1.8 cm de largo, surcada o acanalada por arriba y aquillada por abajo, con frecuencia acompañada con 1 a 3 dientes cortos que coronan a los ángulos de la hoja, de color café oscuro, gris oscuro o casi negro; inflorescencia ascendente o erecta, 1.5-4.3 $\mathrm{m}$ de alto, densa, las flores sobre la mitad superior, el pedúnculo 1.6-6.6 cm de diámetro, con brácteas cartáceas, deltoides, largamente atenuadas hacia el ápice; flores en grupos de tres o a veces en pares, sobre pedicelos trifurcados o bifurcados cortos y gruesos, el perianto $2.6-3.6 \mathrm{~cm}$ de largo, de color blanco crema, blanco verdoso o verde grisáceo muy pálido, los tépalos a veces con tinte rojizo, ovario 1.3-1.7 cm de largo, gruesamente fusiforme, con cuello corto, tubo en forma de embudo, 3-5 x 7-9 mm; tépalos erectos, extendidos, subiguales, 10-19 x 3-4 mm, ampliamente lineales, algo conduplicados y abrazando a los filamentos, los interiores algo aquillados, el ápice redondeado, filamentos rectos, 20-48 mm de largo, insertados sobre el borde del tubo, anteras amarillas; cápsulas de consistencia leñosa o gruesamente coriácea, oblongas a estrechamente oblongas, (1.3-)1.7-2.1 x 0.7-1.1 cm, redondeadas en la base, cortamente apiculadas en el ápice, valvas oblongas a estrechamente oblongas, $0.7-0.9 \mathrm{~cm}$ de ancho, sobre pedicelos 2-5 $\mathrm{mm}$; semillas negras, opacas o lustrosas, 3-5 x 2-3.5 mm, semicirculares a lacrimiformes, reticulado-venosas sobre ambas caras, el margen bajo.

Agave victoriae-reginae se desarrolla sobre escarpes de pendiente pronunciada en la Sierra Madre Oriental en el oeste de Nuevo León y en las serranías transversales que atraviesan Coahuila hasta el este de Durango, así como sobre crestas coronando cerros aislados en el oeste de Nuevo León y extremo este de Coahuila y en menor proporción sobre coluviones en piedemonte. En vegetación de matorral xerófilo y matorral submontano. 
Se reconocen dos subespecies para $A$. victoriae-reginae con base en el hábito de la planta, la forma de las hojas y la distribución alopátrica de los taxa:

1a. Agave victoriae-reginae T. Moore subsp. victoriae-reginae.

Agave consideranti Carr., Rev. Hort. 429. 1875 f. 68. No tipificado. Figs. 1a, 2b, 3b.

Nombres comunes: lechuguilla (siendo claramente diferenciada de la lechuguilla común), maguey noha, maguey de roca, noa, noha.

Plantas acaules o con tallo muy corto no visible, compactas, globosas o deprimido-globosas, ampliamente ovoides cuando inician floración, (20-)30-65 cm de diámetro y hasta $60 \mathrm{~cm}$ de alto, con (150-)280 a aprox. 500 hojas; hojas lanceoladas a estrechamente oblongas, (7-)10-22 cm de largo y 3.6-4.8 cm de ancho, engrosadas ventralmente cerca de la base, en hojas secas el margen córneo continuo hasta el ápice; inflorescencia 1.6-4.3 m de alto; flores con perianto 2.6-3.6 cm de largo, blanco crema o blanco verdoso; cápsulas (1.3-)1.7-2.1 x 0.7-1.1 cm, redondeadas en la base, cortamente apiculadas en el ápice, valvas oblongas, 0.7-0.9 cm de ancho; semillas 4 x 2.5-3.5 mm.

Las hojas son por lo general firmes, aunque en poblaciones de Bustamante, Mina y algunas de La Huasteca son flexibles y delgadas, las juveniles marcadamente plegadas en sentido longitudinal.

Agave victoriae-reginae subsp. victoriae-reginae prospera sobre escarpes de caliza de pendiente muy pronunciada (riscos o "relices"), con frecuencia verticales, en cañones estrechos que forman parte de la Sierra Madre Oriental, subprovincia Gran Sierra Plegada en el oeste de Nuevo León, así como sobre crestas calizas coronando sierritas bajas en el oeste de Nuevo León y el extremo este de Coahuila, a veces en coluviones en piedemonte, entre los 564 y los 1684 m s.n.m. (Fig. 5). Las poblaciones más grandes se encuentran en el Cañón de La Huasteca (González, 2008), una parte del Parque Nacional Cumbres de Monterrey, principalmente en matorrales xerófilos sobre escarpes donde predominan Agave bracteosa, A. lechuguilla, A. striata, Hechtia spp. y Dasylirion berlandieri. Sobre coluviones en piedemonte crece en matorral xerófilo y matorral submontano de Helietta parvifolia, Cordia boissieri, Acacia farnesiana, A. amentacea, Celtis pallida, Havardia pallens, Aloysia gratissima, Leucophyllum texanum, Diospyros texana, Croton fruticulosus, Cylindropuntia leptocaulis, C. imbricata, A. lechuguilla, A. striata, Selaginella sp. 
Acta Botanica Mexicana 95: 65-94 (2011)
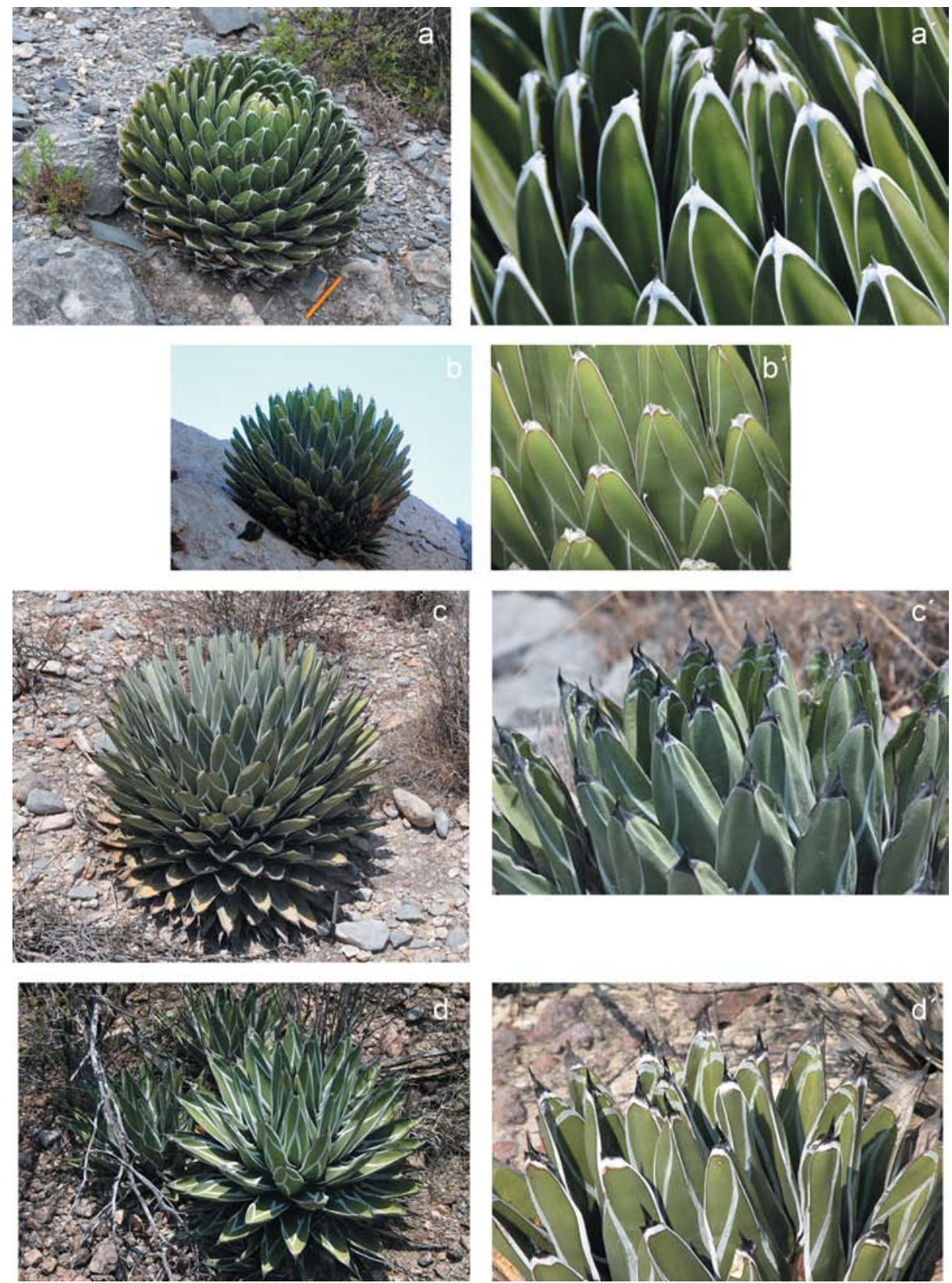

Fig. 1. Hábito y acercamiento de hojas de: a. Agave victoriae-reginae subsp. victoriaereginae; b. A. victoriae-reginae subsp. swobodae; c. A. nickelsiae; d. A. pintilla. 
y Wedelia hispida. En lugares más protegidos el matorral submontano presenta arbolitos de Helietta parvifolia, Acacia berlandieri y Gochnatia hypoleuca. En la subregión de sierritas del Desierto Chihuahuense A. victoriae-reginae crece sobre las paredes calizas de las crestas de sierritas bajas, en comunidades de matorral xerófilo, a veces con elementos de matorral submontano, destacando Hechtia sp., Helietta parvifolia, Fouquieria splendens, Echinocereus sp. y Opuntia sp.

Ejemplares examinados. MÉXICO, COAHUILA. Municipio Candela. Parte sur de sierrita al SW de Candela, cerca del límite con Nuevo León, 2644'22" N, $100^{\circ} 45^{\prime} 24^{\prime \prime} \mathrm{W}, 570 \mathrm{~m}$, en cresta caliza coronando sierrita, vertiente SW, 1 Jun 2010, L. Reséndiz 156, J. Noriega, S. González (CIIDIR). NUEVO LEÓN. Municipio Bustamante. Sierrita de La Ventana, 26³4'40" N, 100³9'47" W, 700 m, M. González 4124, A. Torres, S. González (CIIDIR); ibid., 26³4'18" N, 100³9'29" W, 706 m, 31 May 2009, L. Reséndiz 128, A. Torres (CIIDIR, ENCB); ibid., 26³4'46" N, 100³9'58" W, 695 m, 31 May 2009, L. Reséndiz 129, A. Torres (CIIDIR, MEXU); ibid., L. Reséndiz 129b, A. Torres (CIIDIR); municipio Mina. Cerro de las Ventanas, 2557'56" N, 100³6'7" W, 645 m, 8 May 2009, L. Reséndiz 116, M. González, S. González, L. López y F. Mercado (CIIDIR, ENCB, MEXU); ibid., L. Reséndiz 117, M. González, S. González, L. López y F. Mercado (CIIDIR); ibid., L. Reséndiz 118, M. González, S. González, L. López y F. Mercado (CIIDIR); municipio Santa Catarina. Cañón de la Huasteca (sitio 14), 25³9' N, 100³0' W, 7 May 2009, L. Reséndiz 115, M. González, S. González, L. López y F. Mercado (CIIDIR); ibid., frutos de otro individuo, L. Reséndiz 115-b (CIIDIR); Cañón de la Huasteca (sitio 15.3), 25³8'34" N, 100²8'46" W, 807 m, 7 May 2009, L. Reséndiz 113, M. González, S. González, L. López y F. Mercado (CIIDIR); La Huasteca, Cañón de Ballesteros, 25³8'18" N, $100^{\circ} 27^{\prime} 9 "$ W, 800 m, conglomerado, 16 Jun 2009, I. Cabral C. s.n. con investigadores de Santa Ana Bot. Garden (ANSM); Cañón de la Huasteca (sitio 15.5), 25³8' N, 100²8" W, 807 m, L. Reséndiz 114, M. González, S. González, L. López y F. Mercado (CIIDIR); Cañón de la Huasteca, km 4, 25³7'31" N, 100²7'36" W, 745 m, 30 May 2009, L. Reséndiz 125b, A. Torres (CIIDIR, ENCB); Cañón de la Huasteca, camino cerro El Panal por Cañón Guitarritas, 2535'35" N, 100³1'1" W, 1180 m, 16 Dic 2006, I. Cabral C. 2308 e hijos (ANSM); Cañón de la Huasteca, después de la cortina, lado derecho, 2533'43" N, 100²4'17" W, 873 m, 30 May 2009, L. Reséndiz 127, A. Torres (CIIDIR, ENCB); Cañón de la Huasteca, al NE de El Pajonal por el camino a Santa Catarina, 2529'34" N, 100²3'8" W, 1450 m, sobre coluvión, 5 May 2009, L. Reséndiz 111, M. González, S. González, L. López y F. Mercado (CIIDIR, ENCB, MEXU); Cañón de la Huasteca, El Pajonal, 25²9'37" N, 100²3'9" W, 1432 
m, 30 May 2009, L. Reséndiz 126, A. Torres (CIIDIR, ENCB); Cañón de la Huasteca, km 4, 2537'31" N, 100²7'36" W, 745 m, 30 May 2009, L. Reséndiz 125, A. Torres (CIIDIR, ENCB); Cañón de la Huasteca, 3 Jun 1967, J. Marroquín s.n. (MEXU); ibid., 24 May 1979, C. de León 19 (UNL(2)); ibid., end of dirt road at gravel pit, 2 Aug 1972, Lyle McGill 9472, R. Brown y D.J. Pinkava (ENCB); Cañón de la Huasteca (sitio 6.2), 25³9' N, 100³0' W, 6 May 2009, L. Reséndiz 112, M. González, S. González, L. López y F. Mercado (CIIDIR).

1b. Agave victoriae-reginae subsp. swobodae J. J. Halda, Acta Mus. Richnov. Sect. Nat. 7(2): 71. 2000. Holotipo: Mexico septentrionalis, Coahuila, in collibus petrosis non procul a vico Parras, solo calcárico, ca. 1800 m supra mare. PR no. JJH8504315, leg. J.J. Halda 10.4.1985. (n.v.). Fig. 1b, 2a, 3a.

Nombres comunes: maguey noha, noa, noha.

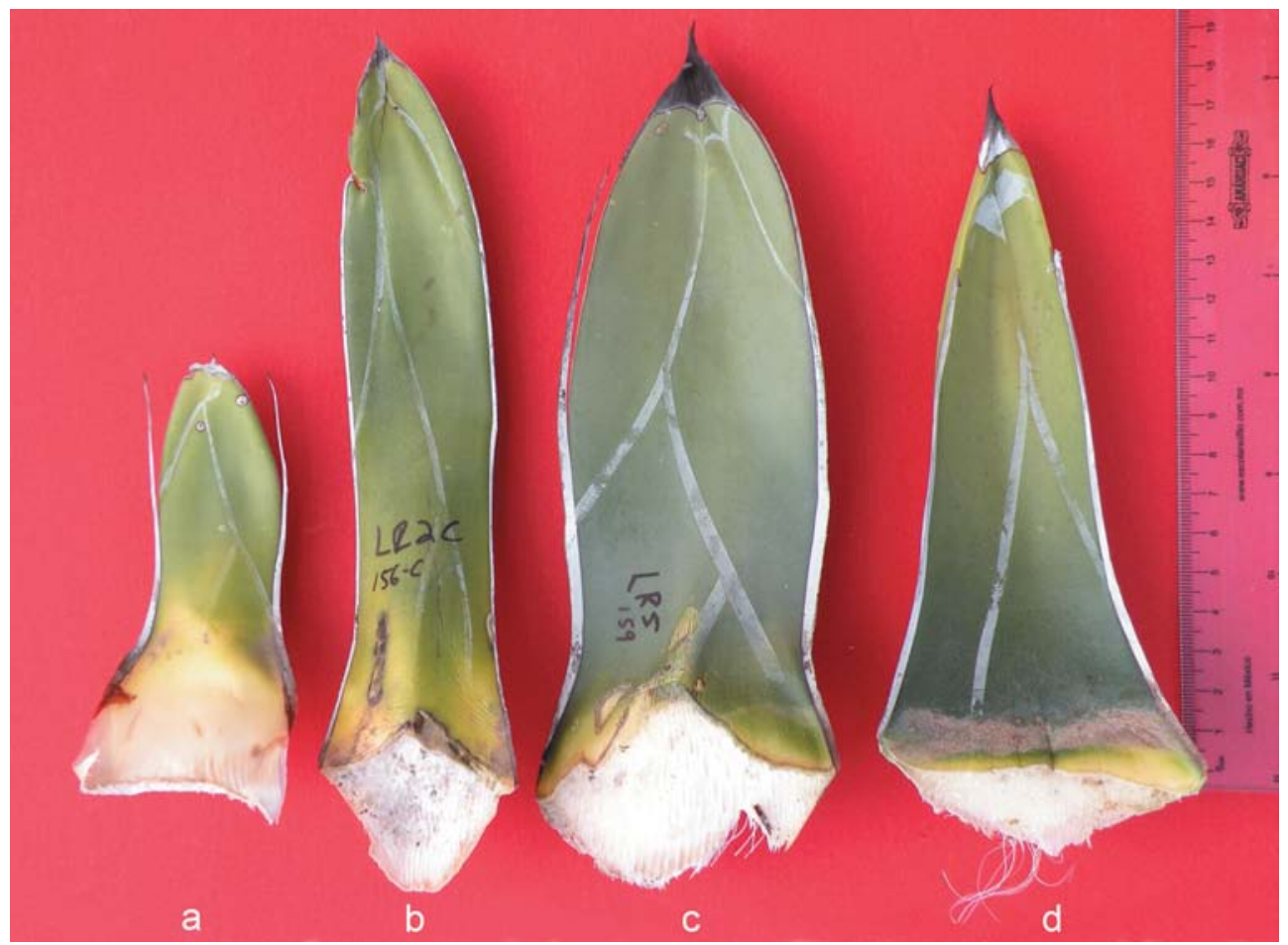

Fig. 2. Comparación de hojas de: a. Agave victoriae-reginae subsp. swobodae; b. A. victoriaereginae subsp. victoriae-reginae; c. A. nickelsiae; d. A. pintilla. 
Plantas acaules o con un corto tallo cubierto de hojas, oblongo globosas a subcilíndricas (en forma de barrilito) cuando maduras, compactas, 20-35 cm de diámetro, hasta de $35 \mathrm{~cm}$ de alto, con 70 a aprox. 180 hojas; hojas estrechamente oblongas a angostamente triangulares, $6-12 \mathrm{~cm}$ de largo y 1.5-4.5 cm de ancho, ventralmente planas a cóncavas cerca de la base, en hojas secas el margen córneo continuo hasta el ápice o frecuentemente desprendido en la parte distal; inflorescencia $1.6-4.3 \mathrm{~m}$ de alto; flores con perianto 2.6-3.2 cm de largo, tubo y cuello blanco verdoso, tépalos blanco rosados o rojizos en la parte interior, filamentos y estilo rosa púrpura pálido, anteras amarillo pálido; cápsulas estrechamente oblongas, 1.7-1.9 x 0.7-0.9 cm, valvas 0.7-0.8 cm de ancho, semillas 3 x $2 \mathrm{~mm}$.

Agave victoriae-reginae subsp. swobodae fue descrita (Halda, 2000) con base en el hábito de la planta y por tener flores y semillas "más grandes". Aunque el tamaño de las flores se encuentra dentro de la variación que se presenta en $A$. victoriae-reginae subsp. victoriae-reginae y las semillas de la subespecie swobodae son más pequeñas, se acepta el reconocimiento de esa subespecie aplicando los criterios de Haig et al. (2006) de discreción en los caracteres y separación de las poblaciones.

Agave victoriae-reginae subsp. swobodae se encuentra sobre escarpes de las extensiones de la Sierra Madre Oriental a través del Desierto Chihuahuense (Serranías Transversales) en el sur de Coahuila y este de Durango, sobre calizas, rara vez en coluviones de piedemonte, entre los 865 y 1550 m s.n.m. (Fig. 5). En matorral xerófilo en el que predominan Hechtia texensis, $H$. podantha, Agave lechuguilla, A. striata, A. asperrima, Yucca rigida, Fouquieria splendens, Opuntia rufida, Euphorbia antisyphilitica, Echinocereus sp., Jatropha dioica y Dasylirion sp. En sitios con coluvión en la base de riscos al matorral xerófilo se mezclan elementos de matorral submontano, principalmente Acacia berlandieri y Gochnatia hypoleuca.

Ejemplares examinados. MÉXICO, COAHUILA. Municipio San Pedro de las Colonias. Al NE de San Pedro de las Colonias, por la carretera a Cuatro Ciénegas, 26 $6^{\circ} 37^{\prime \prime} \mathrm{N}, 102^{\circ} 44^{\prime} 38^{\prime \prime} \mathrm{W}, 1044 \mathrm{~m}$, base de riscos en el tercio inferior del cerro, 1 Jun 2010, L. Reséndiz 155, J. Noriega (CIIDIR); municipio Viesca. Cerro de las Noas en el cañón de Ahuichila; camino de Viesca a Ahuichila, 2511'24" N, 102³8'59" W, 1292 m, escarpe, 12 Ago 2009, L. López 594, T. Tapia y M. González (CIIDIR); ibid., 2511'15" N, 102³9'2" W, 1262 m, escarpe exposición E, 12 Ago 2009, L. López 594b, T. Tapia y M. González (CIIDIR); Cañón de Ahuichila, 1250 m, ladera calcárea, 22 Ago 1991, J. I. Calzada 17379, C. Toledo y J. Blando 
(MEXU-2); Frentón de Ahuichila, ca $6.5 \mathrm{~km}$ al SW de Ahuichila, 25²'30" N, 10240'20" W, sobre escarpes, 12 Ago 2009, J. Tapia s.n., S. Tapia, T. Tapia, M. González (CIIDIR); Sierra del Mármol, 28 km al S de Viesca, camino a Ahuichila, $3 \mathrm{~km}$ al S del rancho, $1300 \mathrm{~m}$, ladera caliza, 21 Jun 1994, A. García-Mendoza 5961, S. Franco y J. Reyes (MEXU); Sierra del Mármol, 28 km al S de Viesca, camino a Ahuichila, 1300 m, ladera caliza, 30 Ago 2000, A. García-Mendoza 6955 (MEXU). DURANGO. Municipio Lerdo. Picacho de León Guzmán, 25³0'28" N, 10340'13" W, 1211 m, 13 Ago 2009, L. López 598, M. González (CIIDIR); Cañón Fernández, aprox. $2.5 \mathrm{~km}$ al N de la entrada por el Cañón del Borrego, 25¹9'33" N, 103⒋'7" W, 1250 m, en risco sobre ladera caliza, 9 Dic 2003, L. Reséndiz 15, R. Galván, L. López, S. González y M. Pinedo (CIIDIR, ENCB); ibid., 14 May 2008, L. Reséndiz 108 M. González, S. González, L. López (CIIDIR, ENCB, IEB, MEXU); ibid., $2 \mathrm{~km}$ al $\mathrm{N}$ de Graceros, por el camino a la presa Francisco Zarco, 2516'10" N, 10345'5" W, 1450 m, sobre risco, 12 May 2008, L. López 530, F. Mercado y D. Ramírez (CIIDIR, ENCB, IEB, MEXU); Cañón Fernández, ca. 2 km al S de Graceros, ladera del Cerro Mulato, 2514'23" N, 10344'22" W, 1267 m, L. Reséndiz 150, M. González y L. López (CIIDIR); Graceros, 2 km adelante, 13 km al E de la desviación a la presa Fco. Zarco, 1200 m, ladera caliza, 22 Jun 1994, A. García-Mendoza 5965, S. Franco y J. Reyes (MEXU).

2. Agave nickelsiae Goss. ex Rol.-Goss., Hort. Amer. ex Rev. Hortic. (Revue Horticole): 579. 1895 (sub 'nickelsi'). Agave victoriae-reginae T. Moore f. nickelsiae (Rol.-Goss.) Trel., Contr. U.S. Nat. Herb. 23: 140. 1920. Neotipo (designado por Breitung, 1960): Fig. 53, p. 26, vol. 32 en Cact. Succ. J. (Los Angeles). 1960. Figs. 1c, 2c, 3c.

Agave victoriae-reginae var. laxior Berger, Hort. Mortol., 15, 364. 1912. Agave ferdinandi-regis A. Berger, Die Agaven, Beiträge zu einer Monographie 90. 1915. Tipo por designarse (planta mostrada en la Exhibición de Paris, 1900 con varias otras de México y luego en Jardín Nabonnand, de donde Berger la recibió en 1903).

El nombre de la especie se dedicó en honor a Mrs. Anna B. Nickels, horticultora de Texas que dio a conocer la planta.

Nombre común: no registrado en campo durante este trabajo. La denominación de "pintilla" se indica para la especie en una manifestación de impacto ambiental (Anónimo, 2007); Trelease (1920) cita a su vez la de “pintillo”, mismo que se aplica en Durango para A. pintilla. 
Rosetas cespitosas, rara vez solitarias, no surculosas, acaules o con un tallo corto no visible (cubierto de hojas), hasta de $75 \mathrm{~cm}$ de diámetro y hasta $65 \mathrm{~cm}$ de alto, subcompactas o abiertas; hojas 170 a 280, de color verde grisáceo a verde opaco, con bandas blancas sobre las dos caras y los márgenes, puberulentas, oblongas, angostadas gradualmente hacia el ápice, no curvadas hacia el centro de la planta, dorsalmente aquilladas cerca del ápice o sobre la mitad distal de la cara abaxial, ventralmente cóncavas excepto hacia la base donde son gruesas y marcadamente convexas a aquilladas, 13-23 cm de largo y 5.5-8.5 cm de ancho; márgenes córneos, blancos, 3-5 mm de ancho, enteros, el margen continuo hacia la base y hacia el ápice o a veces desprendido en la mitad distal; ápice de la hoja redondeado, franja blanca apical inconspicua, 1(-2) mm de ancho, destacando el color negro de la espina; espina de color casi negro, piramidal a lanceolada, gruesa, 2-2.8 cm de largo, ampliamente acanalada por arriba y redondeadamente aquillada por abajo, la base amplia y marcadamente decurrente sobre los ángulos de la hoja, usualmente con 3 dientes adyacentes que coronan a los ángulos de la hoja; inflorescencia erecta, densa, el pedúnculo robusto, $4.5-6.5 \mathrm{~m}$ de alto y hasta de $6.5 \mathrm{~cm}$ de diámetro, con brácteas cartáceas, deltoides en la base, lineales, largamente atenuadas hacia el ápice; flores usualmente en grupos de tres, sobre pedicelos trifur-
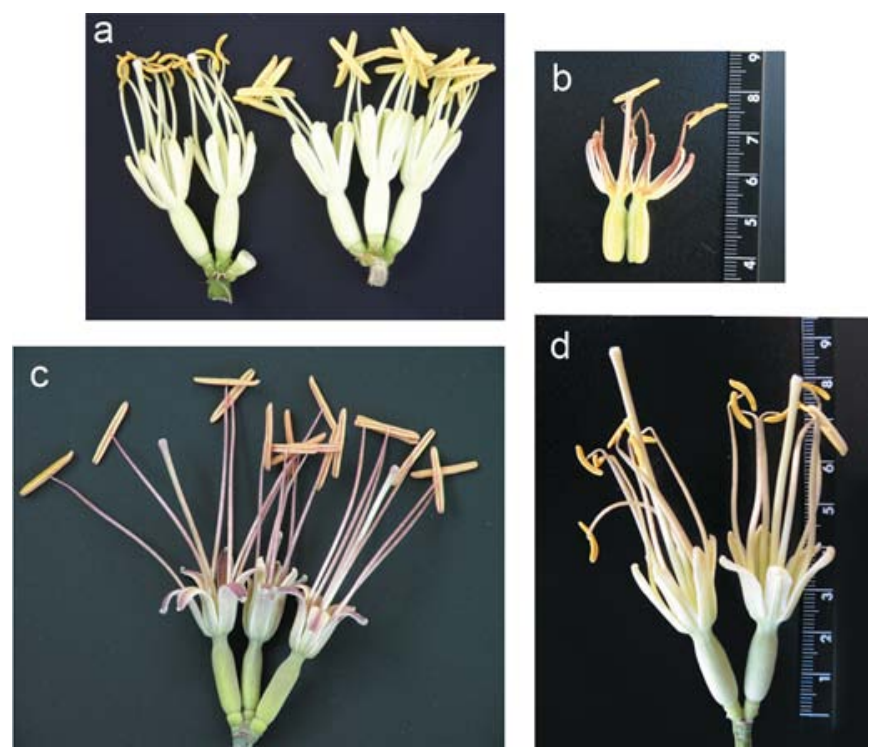

Fig. 3. Comparación de flores de: a. A. victoriae-reginae subsp. victoriae-reginae; b. Agave victoriae-reginae subsp. swobodae, flor abierta longitudinalmente; c. A. nickelsiae; d. A. pintilla. 
cados cortos y gruesos, perianto 4-4.4 cm de largo, ovario 1.8-2.1 cm de largo, gruesamente fusiforme, con cuello corto, tubo en forma de embudo, 3-5 x 8-9 mm; tépalos extendidos, subiguales, 18-22 x 4-6 mm, ampliamente lineales, planos hacia el ápice, los interiores algo aquillados, abrazando a los filamentos solamente en su mitad proximal, la parte distal plana, patente a refleja, con tinción púrpura, el ápice redondeado, filamentos rectos, 60-66 mm de largo, con tinción púrpura, insertados sobre el borde del tubo, anteras amarillas, 11-14 mm de largo; cápsulas y semillas desconocidas.

Agave nickelsiae presenta una clara preponderancia de multiplicación clonal mediante rizomas y una escasa reproducción sexual: durante 2009 no se observaron plantas con inflorescencia ni con indicios de iniciar floración, aunque sí se encontraron escapos secos de A. nickelsiae x A. asperrima; en mayo de 2010 se encontraron escasos individuos de $A$. nickelsiae en floración.

El nombre de $A$. nickelsiae se ha citado como sinónimo de $A$. victoriae-reginae o, cuando se reconoce como especie independiente, bajo la denominación $A$. ferdinandi-regis. Sin embargo, la revisión de la descripción original de A. nickelsiae revela que éste es el nombre legítimo y válido para el taxon. El neotipo designado por Gentry (1982) para A. victoriae-reginae (substituido por el lectotipo designado por Ullrich, 1991a), corresponde a una planta de A. nickelsiae: 12-16 miles NE of Saltillo, Coahuila, along road to Monterrey, June 10-July 5, 1963; elev. 4000-5000 feet, shrub and succulent desert on limestone, Gentry, Barclay \& Arguelles 20043 (DES, MEXU, US).

Agave nickelsiae restringe su distribución al sureste de Coahuila, en la región Arteaga-Ramos Arizpe (Fig. 5), sobre lomeríos de conglomerado con suelo rúdico y abundantes fragmentos de roca caliza aflorando en la superficie. Los suelos predominantes son regosol calcárico (cuando superan los $10 \mathrm{~cm}$ de profundidad) y leptosol calcárico. Se encuentra particularmente sobre los bordes de la parte alta de las lomas, entre los 1500 y $1690 \mathrm{~m}$. En matorral xerófilo con asociaciones vegetales dominadas por: a) Tiquilia canescens y otras boragináceas, Mimosa sp., Agave asperrima x A. nickelsiae, A. lechuguilla con escasas Fouquieria splendens, Viguiera stenoloba, Larrea tridentata y Lophophora williamsii; b) Agave lechuguilla, Buddleja marrubiifolia, Agave striata, Hechtia sp., Dasylirion sp. y escasa Larrea tridentata; c) Parthenium incanum, Buddleja marrubifolia, Aristida sp., asteráceas, Larrea tridentata y Opuntia leptocaulis.

La zona donde se localiza $A$. nickelsiae está sujeta a un alto grado de perturbación por urbanización, bancos de materiales, prácticas de motociclismo y construcción de caminos, lo que causa la fuerte fragmentación del hábitat. 
Ejemplares examinados. MÉXICO, COAHUILA. Municipio Ramos Arizpe. Ramos Arizpe, sitio 4, 2531'0" N, 10053'28" W, 1502 m, 10 May 2009, L. Reséndiz 123, M. González, S. González, L. López y F. Mercado (CIIDIR, ENCB, MEXU); Ramos Arizpe, al SE, sitio 1-3, 2530'38" N, 10054'4" W, 1502 m, en ladera de loma, 10 May 2009, L. Reséndiz 124, M. González, S. González, L. López y F. Mercado (CIIDIR); Ramos Arizpe, cerca de sitio 2-3, 2530'37" N, 10053'36" W, 1520 m, 9 May 2009, L. Reséndiz 121, M. González, S. González, L. López y F. Mercado (CIIDIR); rancho El Saucillo de Abajo, al SE de Ramos Arizpe, 2530'8" N, 10054'36" W, 1530 m, en parte alta de loma, 2 Jun 2010, L. Reséndiz 159, J. Noriega, S. González, T. Espinoza Hernández (CIIDIR); predio al lado del rancho El Saucillo de Abajo, al SE de Ramos Arizpe, 2529'54" N, 10054'46" W, 1537 m, en margen NW de loma, 2 Jun 2010, L. Reséndiz 158, J. Noriega, S. González, T. Espinoza Hernández (CIIDIR); Agave nickelsiae x A. lechuguilla, ibid., 2529'43" N, 10054'43" W, 1530 m, 2 Jun 2010, L. Reséndiz 157, J. Noriega, S. González, T. Espinoza Hernández (CIIDIR); vicinity of Saltillo, A. nickelsiae x A. asperrima, 1 Feb 1952, H. S. Gentry 11530 (MEXU); ibid., A. nickelsiae x A. asperrima, Jun 10-Jul 5 1963, H. S. Gentry 20044, Barclay y Argüelles (MEXU-2). Municipio Arteaga. Loma Alta, al N de Arteaga; Sitio 5-4, 2528'31" N, 10051'38" W, 1688 m, 9 May 2009, L. Reséndiz 119, M. González, S. González, L. López y F. Mercado (CIIDIR).

3. Agave pintilla S. González, M. González \& L. Reséndiz, sp. nov. Figs. 1d, 2d, 3d, 4a-f.

Agave victoriae-reginae T. Moore et A. nickelsiae Goss. ex Rol.-Goss. affinis sed rosulis apertis laxis, foliis anguste triangularibus, pallidioribus vel glauco-viridibus, inflorescentia laxiore et floribus geminatis differt. $\mathrm{Ab} A$. victoriae-reginae differt rosulis caespitosis, foliis basi latioribus et floribus majoribus; A. nickelsiae valde affinis sed habitu breviore, foliis minus numerosis, non puberulentis, floribus lobis albidis vel albido-viridibus differt.

Tipo: MÉXICO, Durango: municipio de El Mezquital, aprox. 0.3 km (línea recta) al $\mathrm{N}$ del entronque con el camino a Agua Zarca, al W de la carretera Durango - El Mezquital, 2330'49" N, 104²3'39" W, 1444 m s.n.m., en ladera, matorral xerófilo con elementos de matorral subtropical (Fouquieria splendens, Jatropha dioica, Ipomoea murucoides), L. Reséndiz 131, L. López, F. Mercado y L. Chávez (holotipo: CIIDIR; isotipos: ENCB, MEXU).

Nombres comunes: maguey pintillo, pintillo. 
Acta Botanica Mexicana 95: 65-94 (2011)
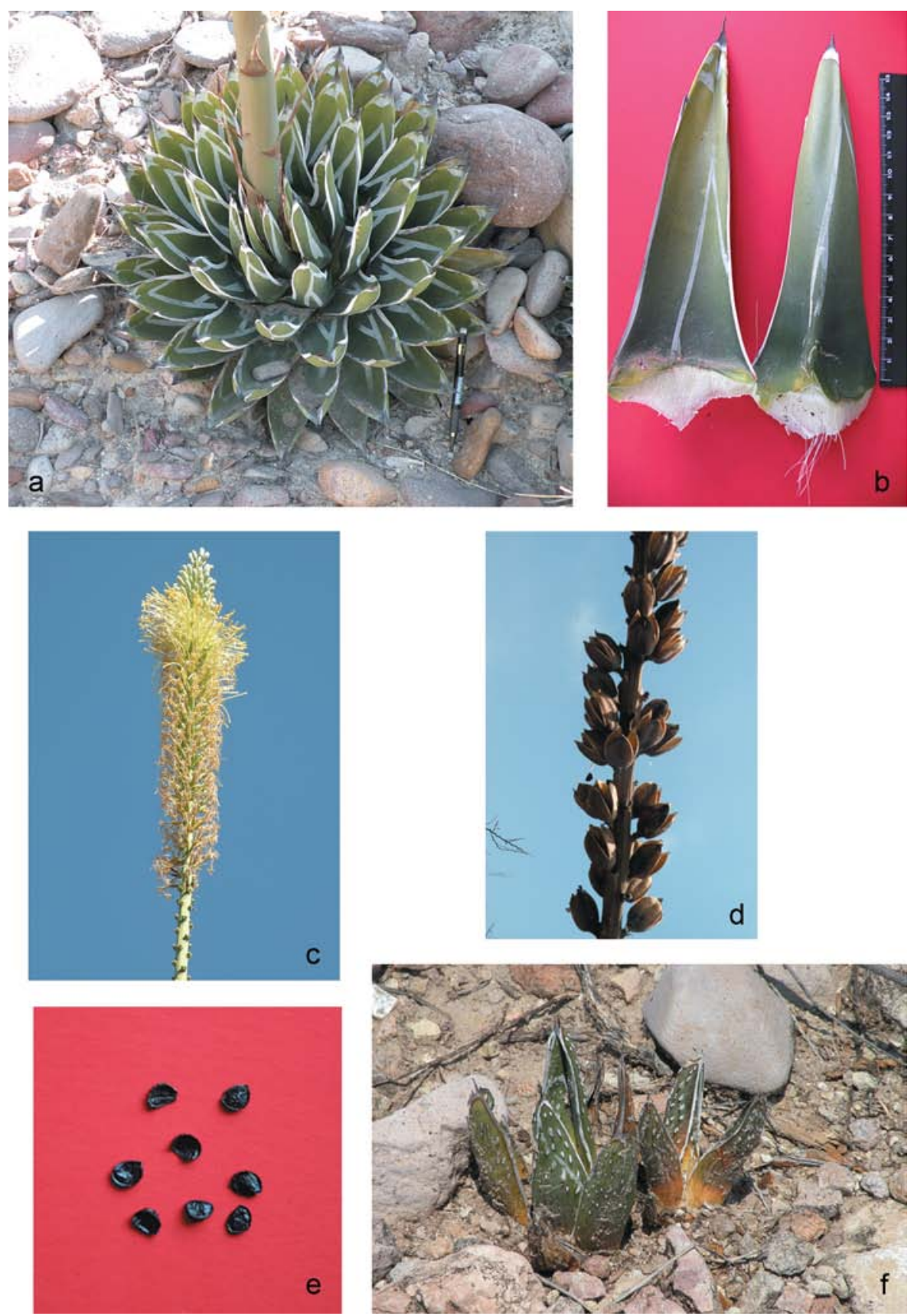

Fig. 4. Agave pintilla: a. roseta con base de escapo y brácteas; b. hojas, vista ventral y dorsal; c. inflorescencia; d. infrutescencia; e. semillas; f. plántula. 
Rosetas cespitosas o solitarias, no surculosas, acaules, 30-60 cm de diámetro y 20-35 cm de alto, laxas, abiertas; hojas 60 a 180, divergentes, de color verde pálido a verde azuloso, con bandas blancas sobre las dos caras y los márgenes, angostamente triangulares, angostadas gradualmente hacia el ápice, más anchas cerca de la base, dorsalmente redondeadas o aquilladas cerca del ápice, ventralmente cóncavas o planas hacia la base, 13-22 cm de largo y 5.8-8 cm de ancho; márgenes córneos, blancos, 3-5 mm de ancho, enteros, continuos hacia la base y hasta el ápice o terminando $2-3 \mathrm{~cm}$ debajo del ápice; ápice de la hoja agudo, destacando el color blanco de la banda apical de 5-10 mm de ancho; espina de color casi negro, angostamente piramidal a lanceolada, 2-2.9 cm de largo, ampliamente acanalada por arriba y aquillada por abajo, no o muy ligeramente decurrente sobre los ángulos de la hoja, usualmente con 3 dientes adyacentes que coronan a los ángulos de la hoja o al menos con una espina dorsal más corta; inflorescencia erecta, relativamente laxa, el pedúnculo 1.6-4.3 $\mathrm{m}$ de alto y hasta de $4.5 \mathrm{~cm}$ de diámetro, con brácteas cartáceas, deltoides, largamente atenuadas hacia el ápice; flores en pares, sobre pedicelos bifurcados, perianto $4-4.4 \mathrm{~cm}$ de largo, ovario 1.8-2.1 cm de largo, gruesamente fusiforme, verdoso, con cuello corto, tubo en forma de embudo, 3-5 x 8-10 mm; tépalos ascendentes a patentes, subiguales, 18-22 x 5-7 $\mathrm{mm}$, ampliamente lineales, algo conduplicados y abrazando a los filamentos en la base, planos hacia el ápice, los interiores algo aquillados, el ápice redondeado, blanquecinos a blanco verdosos, filamentos blanquecino verdosos o con tinción púrpura, rectos, 58$66 \mathrm{~mm}$ de largo, insertados sobre el borde del tubo, anteras de color amarillo crema, 11-15 mm de largo; cápsulas de consistencia leñosa, ampliamente oblongas, 2.2-2.4 x $1.6-1.8 \mathrm{~cm}$, redondeadas en la base, muy cortamente apiculadas, valvas suborbiculares, 1.4-1.5 cm de ancho, sobre pedicelos gruesos 2-4 mm de largo; semillas negras, lustrosas u opacas, 4-5 x 2.5-4 mm, suborbiculares, semicirculares o lacrimiformes, reticulado-venosas sobre ambas caras, el margen bajo.

Agave pintilla se conoce solamente del sureste de Durango, en el municipio de El Mezquital en las estribaciones de la Sierra Madre Occidental (Fig. 5), entre los 1440 y 1580 m s.n.m. Es la especie de distribución más occidental dentro del complejo. Aunque la zona donde se desarrolla se ubica hacia la vertiente oriental de la Sierra Madre Occidental, $A$. pintilla es la única especie del complejo $A$. victoriae-reginae que se desarrolla en una cuenca hidrográfica que drena hacia el Pacífico. Crece sobre lomeríos de conglomerado no consolidado en un área predominantemente volcánica, por lo que pueden encontrarse fragmentos de roca ígnea mezclados. Los suelos dominantes son regosoles calcáricos con abundante $\mathrm{CaCO}_{3}$ y drenaje deficiente debido a la presencia de una capa ócrica, dura y costrosa. En matorral xerófilo de tipo relictual rodeado 
Acta Botanica Mexicana 95: 65-94 (2011)

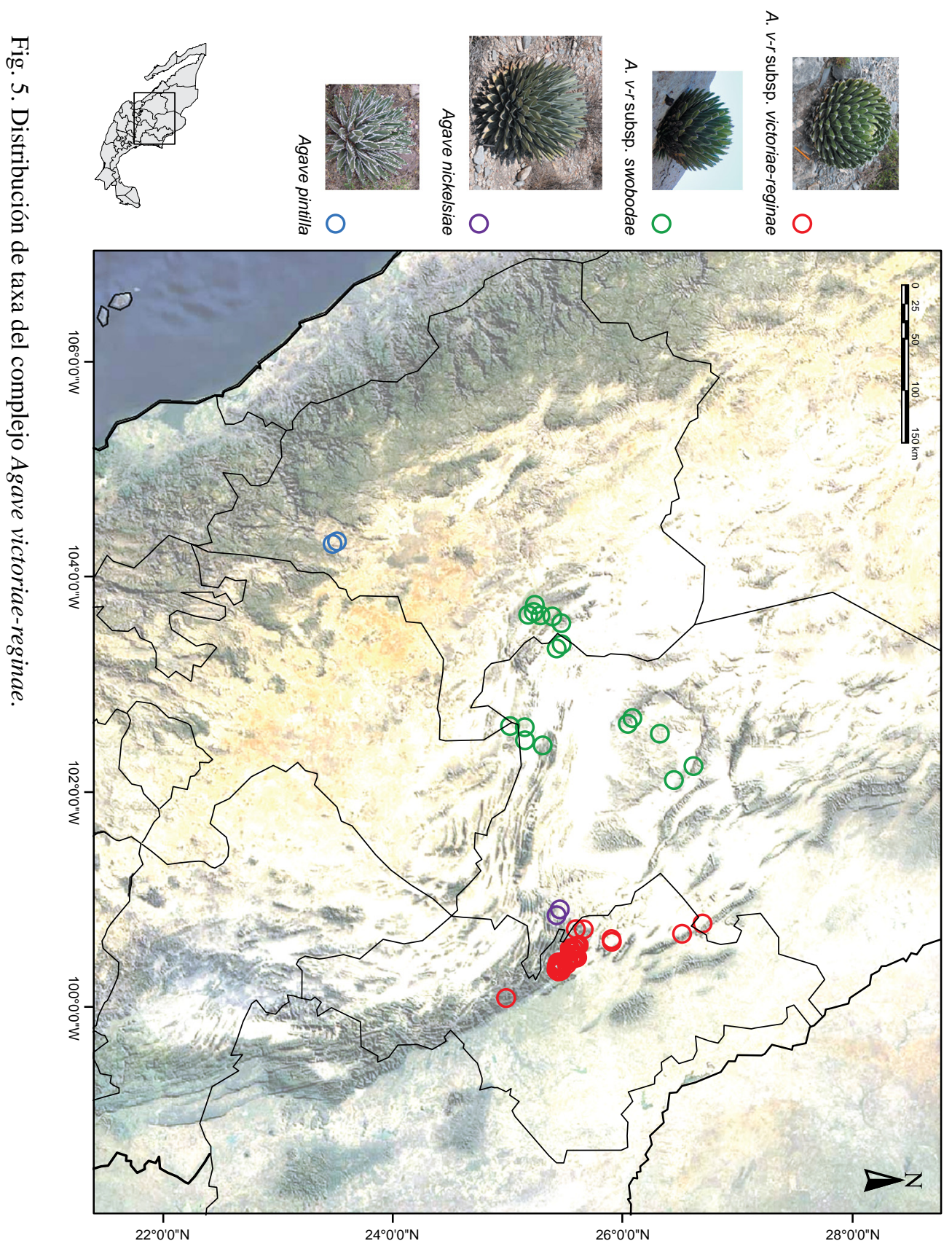


de matorral subtropical y en matorral subtropical, en las siguientes asociaciones: a) Fouquieria splendens, Myrtillocactus geometrizans, Prosopis laevigata y Cercidium sp., con frecuencia con Jatropha dioica, rara vez con Agave durangensis; b) P. laevigata, M. geometrizans, Cercidium sp., Lycium sp., F. splendens e Ipomoea murucoides; c) F. splendens, J. dioica, I. murucoides, L. graveolens; d) Acacia neovernicosa, Krameria sp., Atriplex sp. y F. splendens con Euphorbia antisiphylitica, J. dioica, Cylindropuntia leptocaulis, Agave durangensis, Agave cf. salmiana, Eysenhardtia sp. y M. geometrizans o con I. murucoides, Tecoma stans y L. graveolens.

Agave pintilla presenta reproducción sexual por semilla y asexual por rizomas, siendo la segunda la más común, las plantas de la colonia densa o laxamente agrupadas. El hecho de que individuos maduros de A. pintilla tengan una apariencia similar a la de individuos jóvenes de algunas poblaciones de $A$. victoriae-reginae subsp. victoriae-reginae, aunado a la distribución disyunta de tipo relictual en A. pintilla y al pequeño tamaño de sus poblaciones (resultado en parte de su restricción a sustrato sedimentario en un área con prevalencia de sustrato ígneo), puede interpretarse como que $A$. pintilla ha evolucionado a un ritmo más lento que $A$. victoriae-reginae como resultado del menor número de individuos, menor diversidad de hábitats disponibles y menor oportunidad de intercambio genético. La comparación de perfiles ISTR entre poblaciones del grupo de A. victoriae-reginae (Ávila Sevilla, 2010) muestra que la complejidad más baja, con cinco y seis secuencias, respectivamente, se presenta precisamente en las especies con poblaciones muy reducidas: $A$. nickelsiae y A. pintilla, lo que parece apoyar la hipótesis de escaso intercambio genético.

El epíteto específico alude al nombre común, pintillo, con el que se conoce esta planta debido a las evidentes listas blancas de las hojas.

A pesar de su pequeño tamaño, la planta fue usada hasta hace unos 15 años para elaborar mezcal, muy apreciado por tener un sabor delicado. Al igual que los otros taxa del complejo A. victoriae-reginae, A. pintilla tiene una alto potencial como especie ornamental gracias a su simetría, tamaño relativamente pequeño y atractivo aspecto.

Ejemplares examinados. MÉXICO, DURANGO. Municipio El Mezquital. Los Pérez, al W, por el camino al ejido Santa Gertrudis, 23³2'45" N, 104²3'35" W, 1482 m, en conglomerado muy intemperizado, blanco,13 Jun 2010, S. González 7650, M. González, L. Reséndiz, L. Pánuco (CIIDIR); Agua Zarca, aprox. 0.3 km (línea recta) al 
$\mathrm{N}$ del entronque con el camino a Agua Zarca, al W de la carretera Durango - El Mezquital, 2330'49" N, 104²3'39" W, 1444 m, 15 Jun 2009, L. Reséndiz 131, L. López, F. Mercado y L. Chávez (CIIDIR, ENCB, MEXU); Agua Zarca, al E, aprox. $0.2 \mathrm{~km}$ al S del entronque, al W de la carretera Durango - El Mezquital, 2330'37" N, 104²3'43" W, 1460 m, 4 Jun 2010, L. Reséndiz 160, J. Noriega, S. González (CIIDIR); Agua Zarca, aprox. $2 \mathrm{~km}$ al E, al W de la carretera Durango - El Mezquital, 2330'36" N, 104²3'42" W, 1453 m, en ladera de loma, 10 Dic 2003, L. Reséndiz 1 (CIIDIR, ENCB); ibid., L. Reséndiz 16, R. Galván, L. López, M. Pinedo, J. L. y S. González (CIIDIR, ENCB); ibid., 1450 m, s/fecha, L. Reséndiz s.n. (ANSM, CFNL, MEXU); ibid., 15 Jun 2009, L. Reséndiz 130, L. López, F. Mercado y L. Chávez (CIIDIR); El Troncón, 2 km al W, por el camino a Temohaya, 2330'06" N, 104²4'48" W, 1490 m, ladera de loma, exp N, 9 Dic 2010, S. González, M. González y L. Ruacho s.n. (CIIDIR).

Hibridación

Durante este trabajo no se detectaron híbridos naturales entre los taxa del complejo Agave victoriae-reginae ni entre A. victoriae-reginae s.s. con otras especies. Las referencias a híbridos de $A$. victoriae-reginae que se encuentran en la literatura (Gentry, 1982, entre otros), se basan en los abundantes híbridos de $A$. nickelsiae con A. asperrima o con A. lechuguilla. Una alta diversidad de híbridos naturales en una población de Agave victoriae-reginae s.s. reportada por Verduzco-Martínez et al. (2009) para un sitio en el Parque Nacional Cumbres de Monterrey, en donde participan A. lechuguilla, A. bracteosa y A. americana (A. asperrima?) pudiera ser una situación muy local.

Un resumen de las frecuencias de hibridación natural en especies del complejo A. victoriae-reginae se presenta en el Cuadro 2. Los datos se basan en observaciones en campo en relación al número de individuos de parentales y de híbridos (número de colonias para el caso de A. nickelsiae) y no necesariamente serán los mismos en experimentos de hibridación.

Por el tamaño, la extensión y la buena salud de sus poblaciones, A. victoriaereginae s.s. no hibridiza con otras especies o lo hace en una frecuencia muy baja. Por otra parte, en A. nickelsiae se observa una alta incidencia de este fenómeno, particularmente con Agave asperrima Jacobi y Agave lechuguilla Torr., siendo mayor la frecuencia con la primera que con la segunda, al contrario de lo que podría esperarse, dado que $A$. asperrima pertenece al subgénero Agave y no al subgénero Littaea en el que se ubica $A$. nickelsiae. Los híbridos con A. asperrima presentan a su vez reproducción asexual y sexual, encontrándose algunas inflorescencias de 
Cuadro 2. Frecuencias de hibridación natural en taxa del complejo Agave victoriae-reginae. Porcentajes estimados a partir de observaciones en campo en relación con el número de individuos de parentales y de híbridos.

\begin{tabular}{lccc}
\hline \multicolumn{1}{c}{$\mathrm{x}$} & A. victoriae-reginae & A. nickelsiae & A. pintilla \\
\hline A. asperrima & 0 & 48.8 & 0 \\
A. lechuguilla & 0 & 19.5 & 0 \\
A. cf. salmiana & 0 & 0 & $<1$ \\
A. victoriae-reginae & 100 & 0 & 0 \\
A. nickelsiae & 0 & 31.7 & 0 \\
A. pintilla & 0 & 0 & $>99$ \\
\hline
\end{tabular}

tipo intermedio entre los dos subgéneros (Fig. 6). La alta frecuencia de cruzamiento de A. nickelsiae con A. asperrima y con A. lechuguilla puede ser resultado, por lo menos parcialmente, de la intensa presión de ramoneo por herbívoros silvestres y al fuerte disturbio a que está sometido su hábitat. La relación entre la incidencia de híbridos y la perturbación del ambiente ha sido discutida por Stebbins (1957) y Grant (1971). Otros casos de alta ocurrencia de este fenómeno en Agave en sitios con alto disturbio se presentan en González Elizondo et al. (2009). Los enjambres híbridos mencionados por Gentry (1982) para A. nickelsiae (tratada en su trabajo bajo el nombre de A. victoriae-reginae) son raros y predominan más bien las colonias de clones de plantas originadas por cruzamientos.

Híbridos entre A. nickelsiae y A. asperrima se han descrito con los siguientes nombres:

a) Agave nigra = Agave asperrima Jacobi x A. nickelsiae (acc. Kolendo, 2009, con A. nickelsiae citado como A. victoriae-reginae).

b) Agave pumila De Smet ex Baker, handbook Amarillideae, 172. 1888 = Agave asperrima x A. nickelsiae. Agave pumila, conocida solamente en cultivo, presenta un marcado dimorfismo, con los individuos juveniles con hojas muy cortas y anchas (Gentry, 1982). Su origen se ha interpretado como hibridación entre A. lechuguilla y A. nickelsiae (citado como "A. victoriae-reginae del este de Saltillo, Coah.”) (Gentry, op. cit.), pero la imagen de una planta madura en el mismo trabajo (pág. 176) con las bases de las hojas gruesas y anchas indica afinidad con A. asperrima.

c) Agave saltilloensis = A. asperrima x A.nickelsiae (acc. Kolendo, 2009, citando a A. nickelsiae como A. victoriae-reginae). 

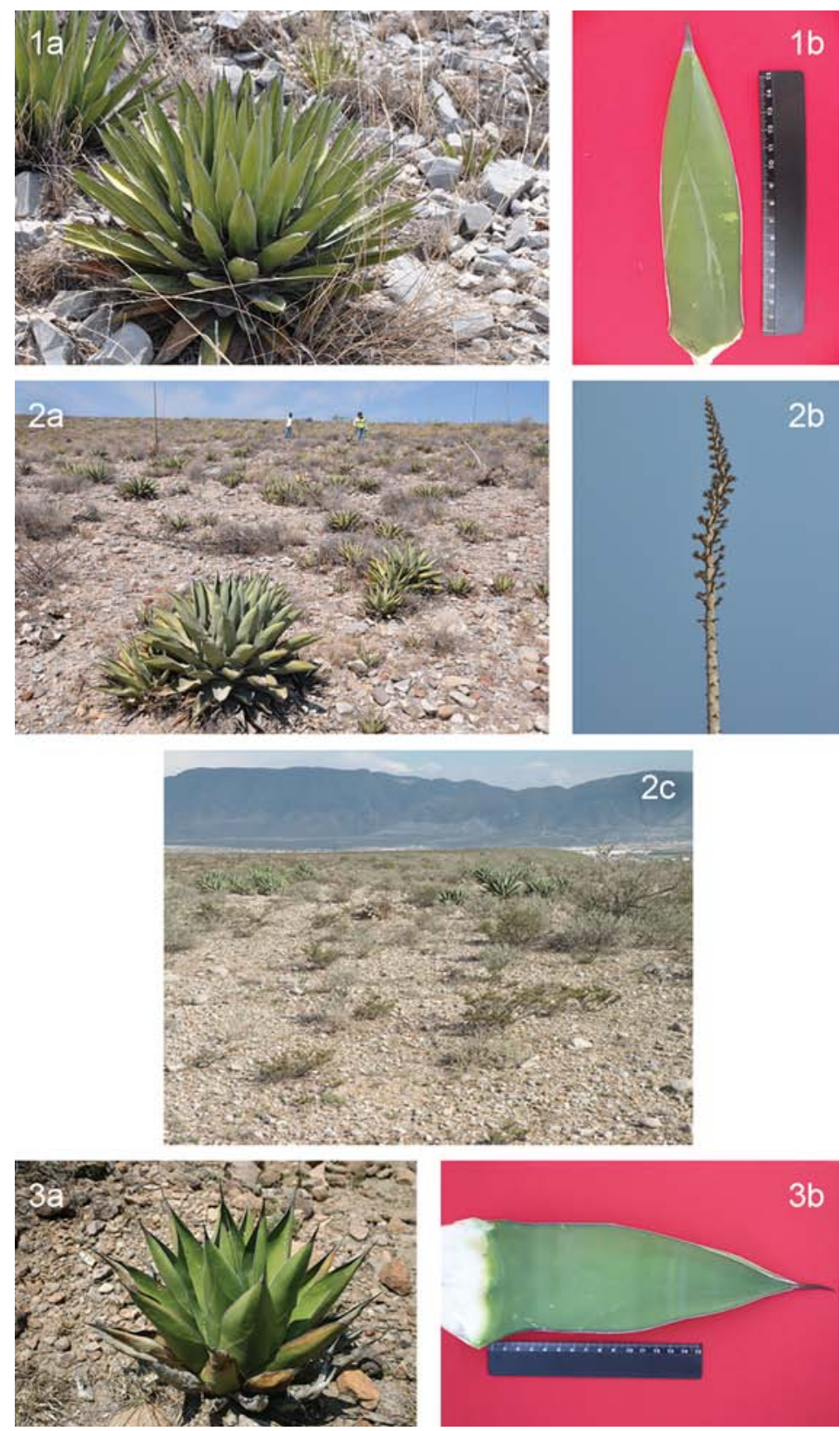

Fig. 6. Híbridos: 1a. A. nickelsiae x A. lechuguilla, 1b. hoja de A. nickelsiae x A. lechuguilla; 2a. A. nickelsiae x A. asperrima, 2b. infrutescencia de A. nickelsiae x A. asperrima, 2c. colonia de A. nickelsiae x A. asperrima; 3a. A. pintilla x A. salmiana, 3b. hoja de A. pintilla $\mathrm{x}$ A. salmiana. 
d) Agave victoriae-reginae f. viridis Breitung, Cact. Succ. J. (Los Angeles) 32: 37. 1960 (sin las bandas blancas) $=$ A. nickelsiae x A. lechuguilla, acc. Alsemgeest et al. 2007).

Ejemplares examinados: Agave nickelsiae x A. asperrima. MÉXICO, COAHUILA. Ramos Arizpe, rancho El Saucillo de Abajo, al SE de Ramos Arizpe, 2530'7" N, 10054'36" W, 1541 m, matorral xerófilo con boragináceas, Mimosa, Fouquieria splendens, Viguiera stenoloba, Larrea tridentata, Lophophora williamsii, en loma de conglomerado con caliza; abundante, forma colonias, 2 Jun 2010, S. González s.n., L. Reséndiz, J. Noriega, T. Espinoza Hernández (CIIDIR); Ramos Arizpe, sitio 1-3, 2530'38" N, 10054'4" W, 1502 m, matorral xerófilo con Parthenium incanum, Buddleja marrubifolia, Aristida, asteráceas, Larrea tridentata, Opuntia leptocaulis, en ladera de loma, conglomerado pedregoso, abundante, forma colonias, 10 May 2009, S. González fotografía, M. González, L. Reséndiz, L. López y F. Mercado.

Agave nickelsiae x A. lechuguilla. MÉXICO, COAHUILA. Arteaga, Loma Alta, al N de Arteaga, 2528'32" N, 10051'38" W, 1690 m, matorral xerófilo con Agave lechuguilla, Buddleja marrubiifolia, Agave striata, Hechtia sp., Dasylirion sp., escasa Larrea tridentata, en ladera de loma caliza con conglomerado; abundante, forma colonias, 9 May 2009, S. González s.n., M. González, L. Reséndiz, L. López, M. Mercado (CIIDIR); Ramos Arizpe, predio al lado de Rancho El Saucillo de Abajo, al SE de Ramos Arizpe, 2529'43" N, 10054'43" W, 1530 m, matorral xerófilo con boragináceas, Mimosa, Fouquieria splendens, Viguiera stenoloba, Larrea tridentata, Lophophora williamsii, en loma de conglomerado con caliza; escasa, en pequeña colonia, 2 Jun 2010, L. Reséndiz 157, J. Noriega, S. González, T. Espinoza Hernández (CIIDIR).

Para A. pintilla se registró un evento de hibridación, siendo éste con Agave salmiana Otto ex Salm-Dyck subsp. crassispina (Trel.) Gentry. El híbrido presenta el color verde intenso y hojas anchas de A. salmiana, pero con margen córneo, dientes muy reducidos y bandas blancas casi imperceptibles (Fig. 6).

Ejemplar revisado: Agave pintilla x Agave salmiana subsp. crassispina: MÉXICO, DURANGO. Municipio El Mezquital. Los Pérez, al W, en terrenos del ejido Santa Gertrudis, al N de la Mesa Atravesada, 2332'49" N, 104²5'0" W, 1574 m, en conglomerado muy intemperizado, L. Reséndiz 161, M. González (CIIDIR).

Se ha sugerido que debido a los orígenes recientes de muchas especies de Agave s.l., la hibridación e introgresión entre especies dificultan resolver sus relaciones 
filogenéticas (Rocha et al., 2006). La notable variación morfológica intra e interpoblacional que presenta $A$. victoriae-reginae s.s. se deriva más bien de la plasticidad de su fenotipo y de su gran variación genética.

Otros nombres registrados para el complejo A. victoriae-reginae

Nombres que corresponden a formas o a cultivares obtenidos con fines ornamentales:

Agave victoriae-reginae f. dentata Breitung, Cact. Succ. J. (Los Angeles) 32: 35. 1960.

Agave victoriae-reginae f. latifolia Breitung, Cact. Succ. J. (Los Angeles) 32: 37. 1960.

Agave victoriae-reginae f. longifolia Breitung, Cact. Succ. J. (Los Angeles) 32: 38. 1960.

Agave victoriae-reginae f. longispina Breitung, Cact. Succ. J. (Los Angeles) 32: 37. 1960.

Agave victoriae-reginae f. ornata Breitung, Cact. Succ. J. (Los Angeles) 32: 37. 1960.

Agave victoriae-reginae f. stolonifera H. Jacobsen, Kakteen Sukk. 11(6): 91, fig. 1960 (nom. inval., Art. 37.1) (Eggli, 2003).

Agave victoriae-reginae f. variegata hort. (s.a.) (nom. inval., Art. 29.1) (Eggli, 2003).

Agave victoriae-reginae var. compacta hort. (s.a.) (nom. inval., Art. 29.1) (Eggli, 2003).

Agave victoriae-reginae var. stolonifera hort. (s.a.) (nom. inval., Art. 29.1) (Eggli, 2003).

\section{AGRADECIMIENTOS}

Muchas personas contribuyeron con información sobre las plantas estudiadas. Los Srs. Santiago Cantú, Tomás Espinoza Hernández, Jesús Tapia, Santiago Tapia y Tomás Tapia, Ascensión Medrano y Luis Pánuco nos guiaron en la búsqueda de poblaciones. En campo y gabinete contamos con el valioso apoyo del Sr. Abraham Torres Soto, Biól. Fermín Mercado Muñoz, Sr. Marcos Pinedo Reyes, Sr. Jorge Noriega Villa y M. en C. David Ramírez Noya. Los Srs. Roberto González Elizondo y Noé González Elizondo proporcionaron apoyo logístico. El Dr. Glafiro Alanís 
Flores, Dr. Carlos Velazco Macías, Dr. Ismael Cabral Cordero, M. en C. Georgina A. Tena González, Biól. Yamil López Bujdud, Biól. Federico Casillas Orona, Biól. Milton Ruiz, Dra. Raquel Galván Villanueva, Dr. Celso Manuel Valencia Castro, Dr. Francisco Valdés Perezgasga y Dr. Urs Eggli aportaron información sobre el grupo de estudio. El Ing. Felipe Lucio y el Dr. Alejandro Espinoza Treviño ayudaron a hacer contacto con personas que conocen poblaciones de A. victoriae-reginae. La Biol. Lizeth Ruacho González, Sergio Heines Silerio y Sra. Olivia Carvajal Palacios apoyaron en el manejo de imágenes. A los curadores de los herbarios ANSM, CFNL, CIIDIR, ENCB, MEXU y UNL se agradecen las facilidades para consulta de muestras. Un agradecimiento especial al Dr. Abisaí García Mendoza por compartir generosamente su conocimiento sobre la taxonomía del grupo, al Ing. Noel Herrera Pedroza por el profesional apoyo en la elaboración de la cartografía, al Dr. William R. Anderson por la orientación para resolver embrollos nomenclaturales y a dos revisores anónimos que aportaron sugerencias que permitieron mejorar el manuscrito. Agradecemos a la Comisión de Operación y Fomento de Actividades Académicas (COFAA) del Instituto Politécnico Nacional (IPN) los estímulos a la investigación. El IPN (proyecto 20090766) y Comisión Nacional para el Conocimiento y Uso de la Biodiversidad (CONABIO, proyecto HS001) aportaron el financiamiento para el desarrollo del trabajo.

\section{LITERATURA CITADA}

Almaraz-Abarca, N., E. A. Delgado-Alvarado, V. Hernández-Vargas, M. Ortega-Chávez, G. Orea-Lara, A. Cifuentes-Díaz de León, J. A. Ávila-Reyes y R. Muñiz-Martínez. 2009. Profiling of phenolic compounds of somatic and reproductive tissue of Agave durangensis Gentry (Agavaceae). Amer. J. Appl. Sci. 6: 1076-1085.

Anónimo. 2010. Norma Oficial Mexicana NOM-059-ECOL-2010. Protección ambiental - Especies nativas de México de flora y fauna silvestres - Categorías de riesgo y especificaciones para su inclusión, exclusión o cambio - Lista de especies en riesgo. Secretaría de Medio Ambiente y Recursos Naturales. Diario Oficial de la Federación. México, D.F. 40 pp.

Anónimo. 2007. Manifestación de impacto ambiental. Modalidad regional. Libramiento norponiente Saltillo - Autopista Saltillo - Monterrey, tramo entronque Monclova IIlímite estatal Coahuila/Nuevo León. Consultoría y Proyectos de Carreteras, S.A. de C.V. 301 pp.

Alsemgeest, W., J. Roosbroek y T. Walderveen. 2007. Agave victoriae-reginae T. Moore. Translation from Succulenta 86(2): 63-69 http://www.agaves.nl/Articles/E_ victoriae\%20reginae.htm (consultado 11 Dic. 2009). 
Ávila Sevilla, Z. E. 2010. Caracterización molecular y química de Agave victoriae-reginae T. Moore (Agavaceae). Tesis maestría en ciencias (Gestión Ambiental). Centro Interdisciplinario de Investigación para el Desarrollo Integral Regional, Instituto Politécnico Nacional, Unidad Durango. Durango. pp.

Carriere, E. A. 1875a. Chronique horticole: L’Agave victoriae-reginae. Rev. Hort. 47(21): 401. Carriere, E. A. 1875b. Agave consideranti. Rev. Hort. 47(22): 427-430.

Chávez Ávila, V. M. y A. Martínez-Palacios. 1996. Evaluación genética y demográfica de Agave victoriae-reginae T. Moore y aplicación del cultivo de tejidos para su conservación. Universidad Nacional Autónoma de México. Bases de datos Sistema Nacional de Información sobre Biodiversidad de México - Comisión Nacional para el Conocimiento y Uso de la Biodiversidad. Proyecto No. B147. México, D.F.

Díaz Ramírez, B., G. González Cervantes, J. A. Cueto Wong, A. Flores Hernández e I. Sánchez Cohen. 2004. Morfología de plántulas de Noa (Agave victoriae-reginae) analizadas por imagen como estudio de aproximación. Agrofaz 4(2): 649-656.

Eguiarte, L. E., J. Larson-Guerra, J. Nuñez-Farfán, A. Martínez-Palacios, K. Santos del Prado y H. T. Arita. 1999. Diversidad filogenética y conservación: ejemplos a diferentes escalas y una propuesta a nivel poblacional para Agave victoriae-reginae en el desierto de Chihuahua, México. Rev. Chil. Hist. Nat. 72: 475-491.

Eguiarte, L. E., A. Castillo y V. Souza. 2003. Evolución molecular y genómica en angiospermas. Interciencia 28(3): 1-8.

Espejo, A. y A. R. López-Ferrari. 1992. Las monocotiledóneas mexicanas, una sinopsis florística. 1. Lista de referencia. Parte I. Consejo Nacional de la Flora de México, A.C.-Universidad Autónoma Metropolitana Iztapalapa. México, D.F. 92 pp.

García-Mendoza, A. 1995. Riqueza y endemismos de la familia Agavaceae en México. In: Linares, E., P. Dávila, F. Chiang, R. Bye y T. Elias (comps.). Conservación de plantas en peligro de extinción: diferentes enfoques. Universidad Nacional Autónoma de México. México, D.F. pp. 51-75.

García-Mendoza, A. 2002. Distribution of the genus Agave (Agavaceae) and its endemic species in Mexico. Cact. Succ. J. 74: 177-187.

García-Mendoza, A. 2003. Distribución del género Agave (Agavaceae) en México. Amaranto 16(2): 2-11.

Gaut, B. S., M. Le Thierry d’Ennequin, A. S. Peek y M. C. Sawkins. 2000. Maize as a model for the evolution of plant nuclear genomes. Proc. Natl. Acad. Sci. 97: 7008-7015.

Gentry, H. S. 1982. Agaves of continental North America. The University of Arizona Press. Tucson. 670 pp.

González, A. 2008. Agave victoriae-reginae. Cactus \& Co. 12(3): 133-150.

González Elizondo, M., M. S. González Elizondo y Y. Herrera Arrieta. 1991. Listados florísticos de México. IX. Flora de Durango. Universidad Nacional Autónoma de México. México, D.F. 167 pp.

González Elizondo, M., R. Galván Villanueva, I. L. López Enriquez, L. Reséndiz Rojas y M. S. González Elizondo. 2009. Agaves-magueyes, lechuguillas y noas-del Estado de Durango y sus alrededores. Centro Interdisciplinario de Investigación para el Desarrollo Integral Regional-Unidad Durango, Instituto Politécnico Nacional-Comisión Nacional para el Conocimiento y Uso de la Biodiversidad. Durango, Dgo. 163 pp. 
Good-Ávila, S. V., V. Souza, B. S. Gaut y L. Eguiarte. 2006. Timing and rate of speciation in Agave (Agavaceae). Proc. National Acad. Sci. 103: 9124-9129.

Grant, V. 1971. Plant speciation. Columbia University Press. New York. 435 pp.

Haig, S. M., E. A. Beever, S. M. Chambers, H. M. Draheim, B. D. Dugger, S. Dunham, E. Elliott-Smith, J. B. Fontaine, D. C. Kesler, B. J. Knaus, I. F. Lopes, P. Loschl, T. D. Mullins y L. M. Sheffield. 2006. Taxonomic considerations in listing subspecies under the U.S. Endangered Species. Act. Conserv. Biol. 20(6): 1584-1593.

Halda, J. J. 2000. Agave victoriae-reginae subsp. swobodae. Acta Mus. Richnov. Sect. Nat. $7(2): 71$.

Hörandl, E. 2010. Beyond cladistics: extending evolutionary classifications into deeper time levels. Taxon 59(2): 345-350.

Kolendo, J. 2009. Issues of Agave nomenclature. http://www.agavepages.co.uk/articles/ nomenclature.html (versión de 25 May 2009)

Martínez-Palacios, A., L. E. Eguiarte y G. R. Furnier. 1999. Genetic diversity of the endangered endemic Agave victoriae-reginae (Agavaceae) in the Chihuahuan Desert. Amer. J. Bot. 86(8): 1093-1098.

Navarro-Quezada, A., R. González-Chauvet, F. Molina-Freaner y L. E. Eguiarte. 2003. Genetic differentiation in the Agave deserti (Agavaceae) complex of the Sonoran desert. Heredity 90: 220-227.

Rocha, M., S. V. Good-Ávila, F. Molina-Freaner, H. T. Arita, A. Castillo, A. García-Mendoza, A. Silva-Montellano, B. S. Gaut, V. Souza y L. E. Eguiarte. 2006. Pollination biology and adaptive radiation of Agavaceae, with special emphasis on the genus Agave. Aliso 22: 329-344.

Trelease, W. 1920. Agave. In: Standley, P. C. (ed.). Trees and shrubs of Mexico. C Contr. U.S. Nat. Herb. 23: 107-142.

Stebbins, G. L. 1957. Variation and evolution in plants. 3a. ed. Columbia University Press. New York. 643 pp.

Thiede, J. 2003. Agavaceae. In: Eggli, U. (ed.) Illustrated handbook of succulent plants. Monocotyledons. Springer. Nueva York. 400 pp.

http://books.google.com.mx/books?id=1bjwYOO_Zt0C\&pg=PA71\&lpg=PA71\&dq=\%22vict oriae-reginae + var. + compacta $\% 22 \&$ source $=$ bl\&ots $=1$ XcTp2m2iS\&sig $=$ Nmn2kot-M3 DhrL7k0CA9yCygNao\&hl=es\&ei=h4YaTPviA4mENNCK4cAF\&sa=X\&oi=book_r esult\&ct $=$ result\&resnum $=2 \& v e d=0 C B o Q 6 A E w A Q \# v=$ onepage $\& q=\% 22$ victoriaereginae\%20var.\%20compacta\%22\&f=false [consultado 10 Junio 2010].

Ullrich, B. 1991a. Agave victoriae-reginae T. Moore. Kakt. And. Sukk. 42(7): 22.

Ullrich, B. 1991b. Zum Verbreitungsgebiet von Agave victoriae-reginae T. Moore. Kakt. And. Sukk. 41(11): 262-263.

Valverde, P. L., F. Vite y J. A. Zavala-Hurtado. 1996. A morphometric analysis of a putative hybrid between A. marmorata Roezl and Agave kerchovei Lem.: Agave peacockii Croucher. Bot. J. Linn. Soc. 122: 155-161.

Verduzco-Martínez, J., C. I. Predo-Rojas y R. Mercado-Hernández. 2009. Caracterización e identificación taxonómica del maguey. Memorias del VII Simposium-Taller Producción y Aprovechamiento del Nopal en el Noreste de México. Revista Salud Pública y Nutrición 2: 75-90. 
Villarreal-Quintanilla, J. A. 2001. Flora de Coahuila. Listados florísticos de México XXIII. Instituto de Biología. Universidad Nacional Autónoma de México. México, D.F. 138 pp.

Villarreal-Quintanilla, J. A. y J. A. Encina-Domínguez. 2005. Plantas vasculares endémicas de Coahuila y algunas áreas adyacentes, México. Acta Bot. Mex. 70: 1-46.

Villaseñor, J. L., E. Ortiz y R. Redonda-Martínez. 2008. Catálogo de autores de plantas vasculares de México. Instituto de Biología, Universidad Nacional Autónoma de México, Comisión Nacional para el Conocimiento y Uso de la Biodiversidad. México, D.F. 40 pp.

Recibido en julio de 2010.

Aceptado en febrero de 2011. 